\title{
Thermoplastic Green Machining for Textured Dielectric Substrate for Broadband Miniature Antenna
}

\author{
Young-Hag $\mathrm{Koh}^{\star \dagger}$ and John W. Halloran* \\ Materials Science and Engineering Department, University of Michigan, Ann Arbor, Michigan 48109-2136 \\ Gullu Kiziltas, Dimitris Psychoudakis, and John Volakis
}

Electrical Engineering and Computer Science Department, University of Michigan, Ann Arbor, Michigan 48109-2121

\begin{abstract}
A textured dielectric substrate for a broadband miniature antenna was fabricated using a thermoplastic green machining. This substrate comprised of three steps with optimized distribution of a dielectric ceramic (Bi-Ba-Nd-Titania; BBNT) and an epoxy. At first, a thermoplastic compound, consisting of BBNT particles and thermoplastic binders, was machined precisely using a mini-computer numeric controlled machine to make a three-dimensional void in the green BBNT body. After appropriate binder removal and sintering, the void in the dense BBNT block was filled with an epoxy to fabricate a textured dielectric substrate. The BBNT sample was characterized by several analyzing tools in terms of machinability, microstructural evolutions, chemical compositions, crystalline phase, and dielectric properties. Bandwidth and gain of the patch antenna with the textured dielectric substrate were measured and compared with the simulated results.
\end{abstract}

\section{Introduction}

$\mathrm{P}$ ATCH antennas are commonly used in wireless communication because they are easy to fabricate and are planar. ${ }^{1-3}$ They are commonly printed on simple dielectric substrates with uniform dielectric constants. The resonance pattern is determined by the patch, ground plane, and dielectric constant of the substrate. More and more, the miniaturizations of patch antennas were necessary to enhance the performances. The physical size can be reduced by the inverse square root of dielectric constant; however, this material suffers from narrow bandwidth, low gain, and degradation of radiation efficiency. ${ }^{4}$

Recently, material optimization procedures have been pursued in order to provide a smaller physical size without degrading pre-specified bandwidth and gain performance. ${ }^{5-7}$ These new materials are composed of more than two dielectric materials with unique textures, named "textured dielectric substrate". Here, "texture" means that the dielectric constant varies at position in electromagnetic field, consequently offering advanced properties due to a particular design.

There are several fabrication processes that can control the local composition and microstructure in two or three dimensions with sub-millimeter spatial resolution, including extrusion, ${ }^{8}$ solid freeform fabrication (SFF) ${ }^{9,10}$ and computer numericcontrolled (CNC)-machining of ceramic green body. ${ }^{11-14}$ Among these processes, the $\mathrm{CNC}$ machining has been regarded

S. C. Danforth—contributing editor

Manuscript No. 10698. Received November 21, 2003; approved October 13, 2004 G910.

${ }^{*}$ Member, American Ceramic Society.

${ }^{\dagger}$ Author to whom correspondence should be addressed. e-mail: kohyh@snu.ac.kr as a cost-effective process. Furthermore, a thermoplastic compound, consisting of $52 \mathrm{vol} \%$ ceramic and $48 \mathrm{vol} \%$ thermoplastic binder, can be machined precisely without generating any defect due to the material removal in a non-brittle manner during machining. ${ }^{11}$

Therefore, in this article, we fabricated a textured dielectric substrate using the thermoplastic green machining. This textured dielectric substrate comprised of three steps with optimized distribution of a dielectric ceramic and an epoxy. A commercial low-temperature co-fired ceramics $(\mathrm{Bi}-\mathrm{Ba}-\mathrm{Nd}-\mathrm{Ti}$ tania, denoted as BBNT) was used, since such low-temperature co-fired ceramics (LTCC), comprised of multiphase glass ceramics or crystallizable glass, ${ }^{15-18}$ can be co-fired with similar silver-alloy metallization with good microwave dielectric properties. A thermoplastic BBNT block was CNC-machined in green stage to make a three-dimensional void. The BBNT material was characterized, including microstructural evolutions, chemical compositions, and crystalline phases, and dielectric properties after sintering at $980^{\circ} \mathrm{C}$ for various dwelling times. After sintering, the void in the dense BBNT material was filled with an epoxy to fabricate a textured dielectric substrate. Bandwidth and gain of the patch antenna with the textured dielectric substrate were measured to evaluate the antenna performance.

\section{Experimental Procedure}

An experimental procedure to fabricate a textured dielectric substrate using a thermoplastic green machining is shown in Fig. 1.

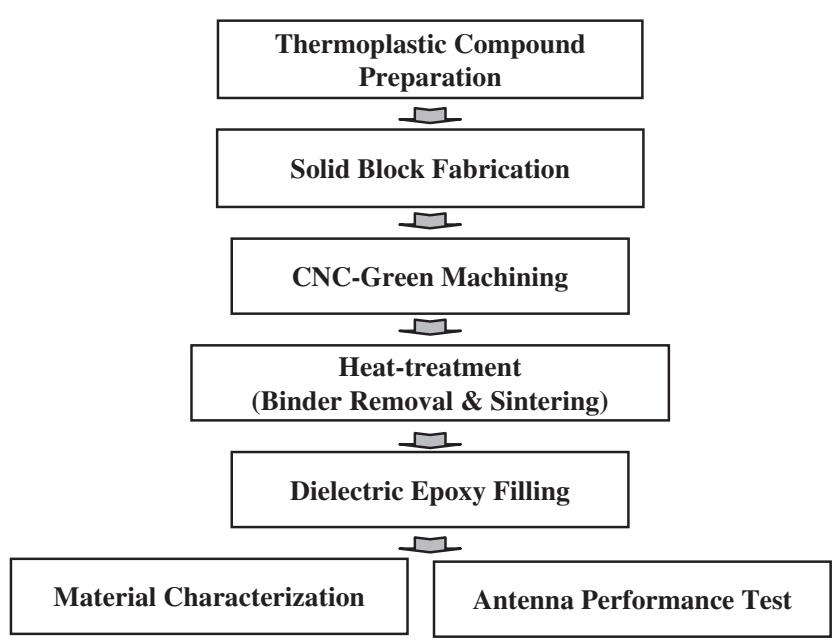

Fig. 1. An experimental procedure to fabricate a textured dielectric substrate using a thermoplastic green machining. 


\section{(1) Thermoplastic Compound Preparation}

A thermoplastic compound was prepared by blending ceramic powders with molten resin. A commercially available LTCC (ULF 101; Ferro Corp., Cleveland, OH) was used as a high dielectric constant material. The powders were ball-milled with 3 vol $\%$ stearic acid (Sigma-Aldrich Co., Milwaukee, WI) as a dispersant in ethanol for $24 \mathrm{~h}$ using alumina balls, and then dried at $85^{\circ} \mathrm{C}$ for more than $24 \mathrm{~h}$. The resin, consisting of ethylene ethyl acrylate (EEA 6182; Union Carbide, Danbury, CT) and isobutyl methacrylate (Paraloid B67; Rohm and Haas, Philadelphia, PA), was melted at $105^{\circ} \mathrm{C}$ using a heated high shear-mixer (PlastiCorder PL 2100 Electronic Torque Rheometer; C. W. Brabender, South Hackensack, NJ). Thereafter, the $52 \mathrm{vol} \%$ powders were gradually added into the molten resin and blended at $130^{\circ} \mathrm{C}$.

\section{(2) Thermoplastic Green Machining}

Once compounded, the thermoplastic compound was compression molded into a solid block using a $38 \mathrm{~mm}$ square mold at $140^{\circ} \mathrm{C}$ with an applied load of $10 \mathrm{MPa}$. The green block (38 $\mathrm{mm} \times 38 \mathrm{~mm} \times 4 \mathrm{~mm}$ ) was machined using a mini-CNC machine (Modela; Roland DGA Corp., Irvine, CA) according to a pre-determined design, consequently leaving a three-dimensional void in the green BBNT block. The larger dimension of the sample was prepared by considering final shrinkage (i.e., $19 \%$ linear shrinkage). The thermoplastic binder was removed by heating slowly to $700^{\circ} \mathrm{C}$ in a nitrogen atmosphere. Thereafter, the samples were sintered at $980^{\circ} \mathrm{C}$ for various dwelling times in air at a heating rate of $3^{\circ} \mathrm{C} / \mathrm{min}$. The densification behavior of BBNT material was monitored using a dilatometer (Theta Industries Inc., Port Washington, NY).

\section{(3) Materials Characterization}

The morphologies of the green and the sintered samples were observed using optical microscopy. The microstructural evolutions, crystalline phases, and chemical compositions of the BBNT materials sintered at $980^{\circ} \mathrm{C}$ for various dwelling times were characterized using scanning electron microscopy (SEM; Philips Electronics N.V., Eindehoven, the Netherlands), X-ray diffraction pattern (XRD; Rigaku International Corp., The Woodlands, TX), and electron probe X-ray micro analyzer (EMPA; Cameca Instruments Inc., Trumbull, CT). Also, inductively coupled plasma atomic emission spectroscopy (ICP-AES, Shimadzu, Kyoto, Japan) was used to analyze the chemical composition of as-received powder.

Dielectric properties of the BBNT samples with a diameter of $10 \mathrm{~mm}$ and height of $5 \mathrm{~mm}$ were measured using a network analyzer (Model HP8720C, Hewlett-Packard, Palo Alto, CA). The relative dielectric constant $\left(\varepsilon_{\mathrm{r}}\right)$ was measured using the post resonator method, ${ }^{19}$ while the $Q_{\mathrm{f}}$ value was measured using the transmission cavity method with a copper cavity and Teflon support. $^{20}$ The measured dielectric properties were related to the microstructural evolutions and densification behavior.

\section{(A) Design of Patch Antenna}

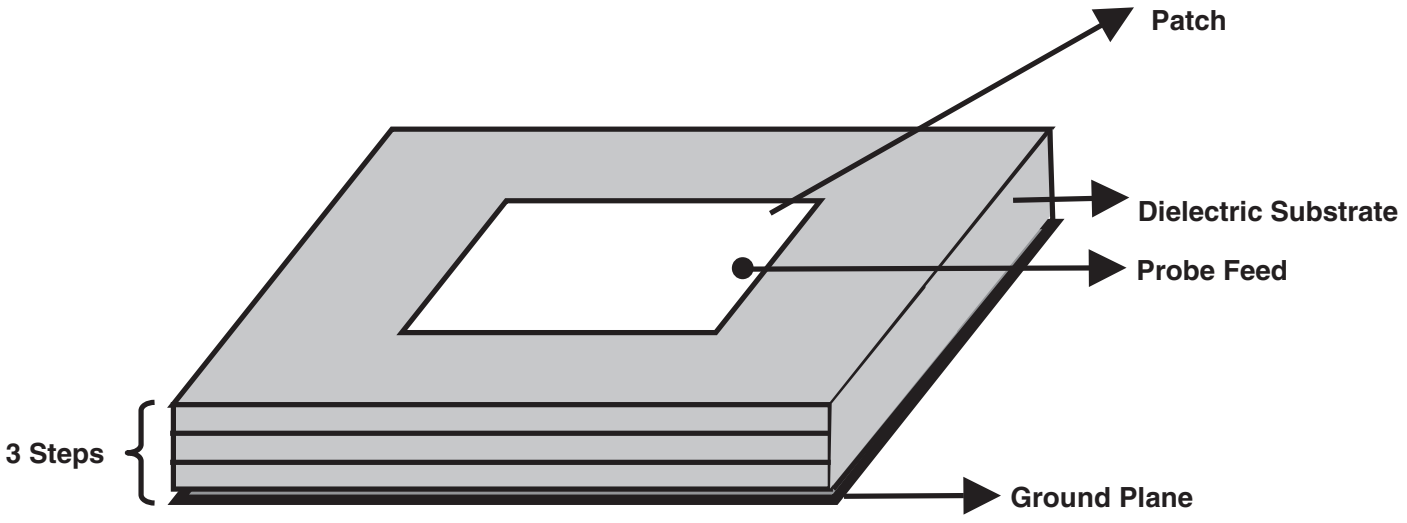

(B) Texture in Each Step

$1^{\text {st }}$ Step

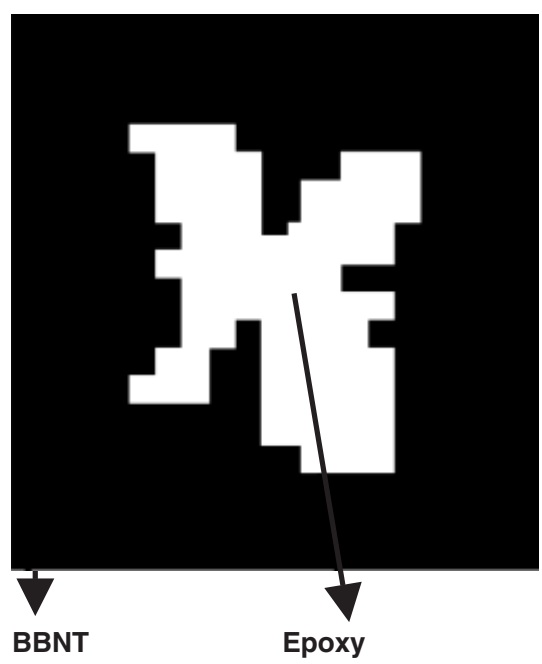

$2^{\text {nd }}$ Step

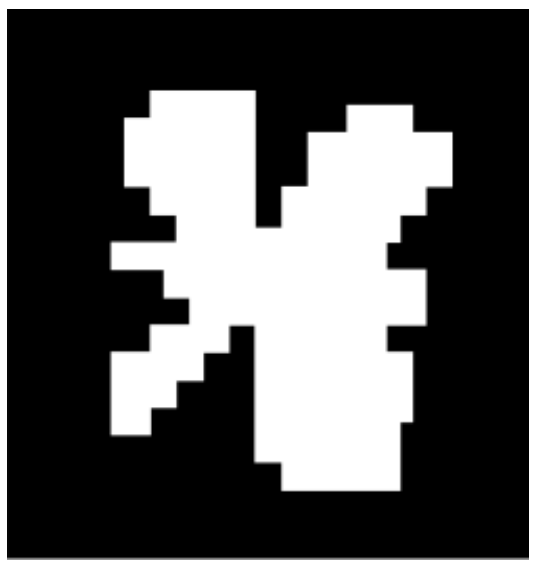

$3^{\text {rd }}$ Step

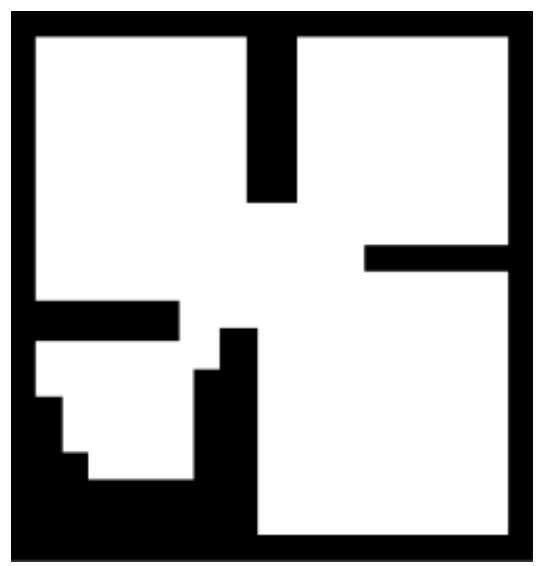

Fig. 2. Schematics illustrating (A) the design of the patch antenna, consisting of patch, dielectric substrate, ground plane, and probe feed, and (B) the texture in each step of textured dielectric substrate. ${ }^{*}$ Dark and bright contrast represent Bi-Ba-Nd-Titania (BBNT) and epoxy region, respectively. 


\section{(4) Antenna Performance Measurement}

A textured dielectric substrate was obtained by filling the threedimensional void in the dense BBNT block with a dielectric epoxy (Stycast W19; Emerson \& Cuming, Billerica, MA). A patch antenna was fabricated using the textured dielectric substrate and other components (i.e., patch, ground plane, and probe feed), as shown in Fig. 2(A). A square $12.5 \mathrm{~mm} \times 12.5 \mathrm{~mm}$ metallic patch was placed at the center of the dielectric substrate using silver paint (ECCOCOAT C110-5; Emerson \& Cuming). A probe aperture was selected and placed at the distance of 6.25 $\mathrm{mm}$ from the right lower corner of the patch. To evaluate bandwidth, the usual value of $50 \Omega$ was chosen as the reference input impedance $\left(Z_{0}\right)$. Return loss and gain were measured and compared with the simulated results.

\section{Results and Discussion}

\section{(1) Design of Textured Dielectric Substrate}

An optimized texture was obtained for the operating frequency range of 1-2 GHz, as shown in Fig. 2(B). The details of material design are described elsewhere. ${ }^{7}$ The textured dielectric substrate was composed of three steps. Each step with dimensions of 25 $\mathrm{mm} \times 25 \mathrm{~mm} \times 1.06 \mathrm{~mm}$ consisted of the optimized distribution of BBNT and epoxy as a high and a low dielectric constant material, respectively. The BBNT region was illustrate in dark contrast, while the epoxy regions in bright contrast.

The return losses of the patch antennas with the homogenous and the textured dielectric substrate were simulated, as shown in Figs. 3(A) and (B). Compared with the narrow bandwidth of the homogenous dielectric substrate (Fig. 3(A)), that of the textured dielectric substrate remarkably enhanced (Fig. 3(B)), while maintaining the same physical size. A $5 \mathrm{~dB}$ return loss bandwidth of $19 \%$ and typical $10 \mathrm{~dB}$ return loss of $14 \%$ were obtained. These simulations suggest that the textured dielectric substrate can offer broad bandwidth with miniaturization.

\section{(2) Characterization of Dense BBNT}

The densification behavior of the BBNT sample is shown in Fig. 4. The sample started to shrink at $\sim 650^{\circ} \mathrm{C}$ through the assistance of a glassy phase, and then rapidly increased up to a $15 \%$ linear shrinkage with increasing temperature (Fig. 4(A)). During dwelling at $980^{\circ} \mathrm{C}$, the shrinkage increased gradually and reached the highest value of $19 \%$ after $10 \mathrm{~h}$ (Fig. 4(B)).

As-received powder mainly comprised of a tungsten bronzetype structure corresponding to $\mathrm{Ba}_{6-3 x} \mathrm{Nd}_{8+2 x} \mathrm{Ti}_{18} \mathrm{O}_{54}$, identified by XRD analysis. The presence of $\mathrm{Bi}$ and $\mathrm{Sn}$ as minor phases, confirmed by ICP analyses, is believed to enhance the densification behavior of BBNT. Regardless of the dwelling

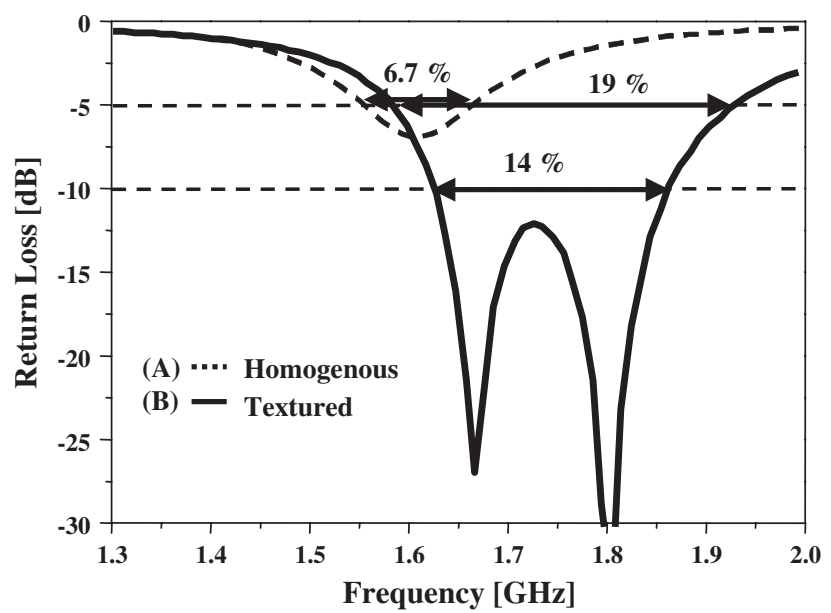

Fig. 3. Return loss of the patch antenna using (A) the homogenous dielectric substrate and (B) the textured dielectric substrate.

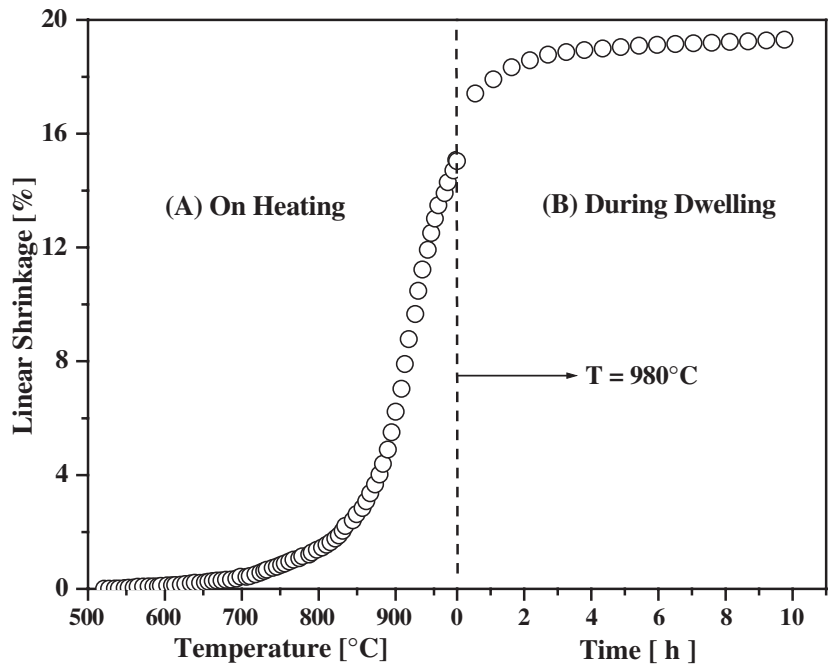

Fig. 4. Densification behavior of $\mathrm{Bi}-\mathrm{Ba}-\mathrm{Nd}-\mathrm{Titania}$ sample (A) on heating at a heating rate of $3^{\circ} \mathrm{C} / \mathrm{min}$ and (B) during dwelling at $980^{\circ} \mathrm{C}$ up to $10 \mathrm{~h}$.

time, the XRD pattern of BBNT sample did not change much, as shown in Fig. 5. $\mathrm{Ba}_{6-3 x} \mathrm{Nd}_{8+2 x} \mathrm{Ti}_{18} \mathrm{O}_{54}$ crystalline structure was detected as a major crystalline structure along with $\mathrm{BaTi}_{4} \mathrm{O}_{9}$ and $\mathrm{Bi}_{3.6} \mathrm{Nd}_{0.4} \mathrm{Ti}_{3} \mathrm{O}_{12}$ crystalline structure as secondary phases.

The microstructural evolutions of the BBNT material sintered at $980^{\circ} \mathrm{C}$ for $10 \mathrm{~h}$ are shown in Figs. 6(A) and (B). At low magnification, extremely large grains were frequently observed on the as-fired surface (Fig. 6(A)). The formation of these grains was attributed to the volatilization of $\mathrm{Bi}$ and $\mathrm{Sn}$ in a glassy phase during sintering. In other words, during dwelling at $980^{\circ} \mathrm{C}$, some of $\mathrm{Bi}$ and $\mathrm{Sn}$ migrated to the surface due to their high vapor pressure, consequently forming a $(\mathrm{Bi}, \mathrm{Sn})$-rich phase. Such large grains on the surface became vigorous with increasing dwelling time. On the other hand, a matrix mainly consisted of fine columnar grains, as shown in Fig. 6(B), which was correspondent to $\mathrm{Ba}_{6-3 x} \mathrm{Nd}_{8+2 x} \mathrm{Ti}_{18} \mathrm{O}_{54}$ crystalline structure.

The effect of $\mathrm{Bi}$ and $\mathrm{Sn}$ on the formation of the large grain was confirmed by energy-dispersive spectrum analyses, as shown in Fig. 7. The matrix grain revealed the peaks of $\mathrm{Ba}, \mathrm{Nd}, \mathrm{Ti}, \mathrm{O}$, and $\mathrm{Bi}$ element, indicating that this grain was a kind of $\mathrm{Bi}$-substituted $\mathrm{Ba}-\mathrm{Nd}-$ titanate (Fig. 7(A)). It is frequently observed

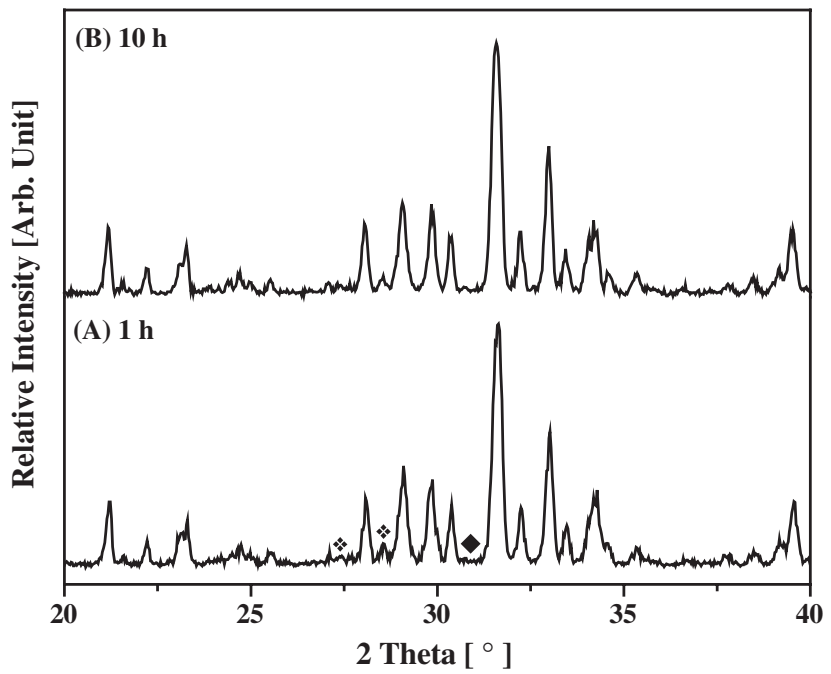

Fig. 5. X-ray diffraction patterns of $\mathrm{Bi}-\mathrm{Ba}-\mathrm{Nd}-\mathrm{Titania}$ material sintered at $980^{\circ} \mathrm{C}$ (A) for $1 \mathrm{~h}$ and (B) for $10 \mathrm{~h}$ in air, illustrating the peaks of $\mathrm{Ba}_{6-3 x} \mathrm{Nd}_{8+2 x} \mathrm{Ti}_{18} \mathrm{O}_{54}$ crystalline structure (not marked) along with the peaks of $\mathrm{BaTi}_{4} \mathrm{O}_{9}(*)$ and $\mathrm{Bi}_{3.6} \mathrm{Nd}_{0.4} \mathrm{Ti}_{3} \mathrm{O}_{12}(\bullet)$ as secondary phases. 

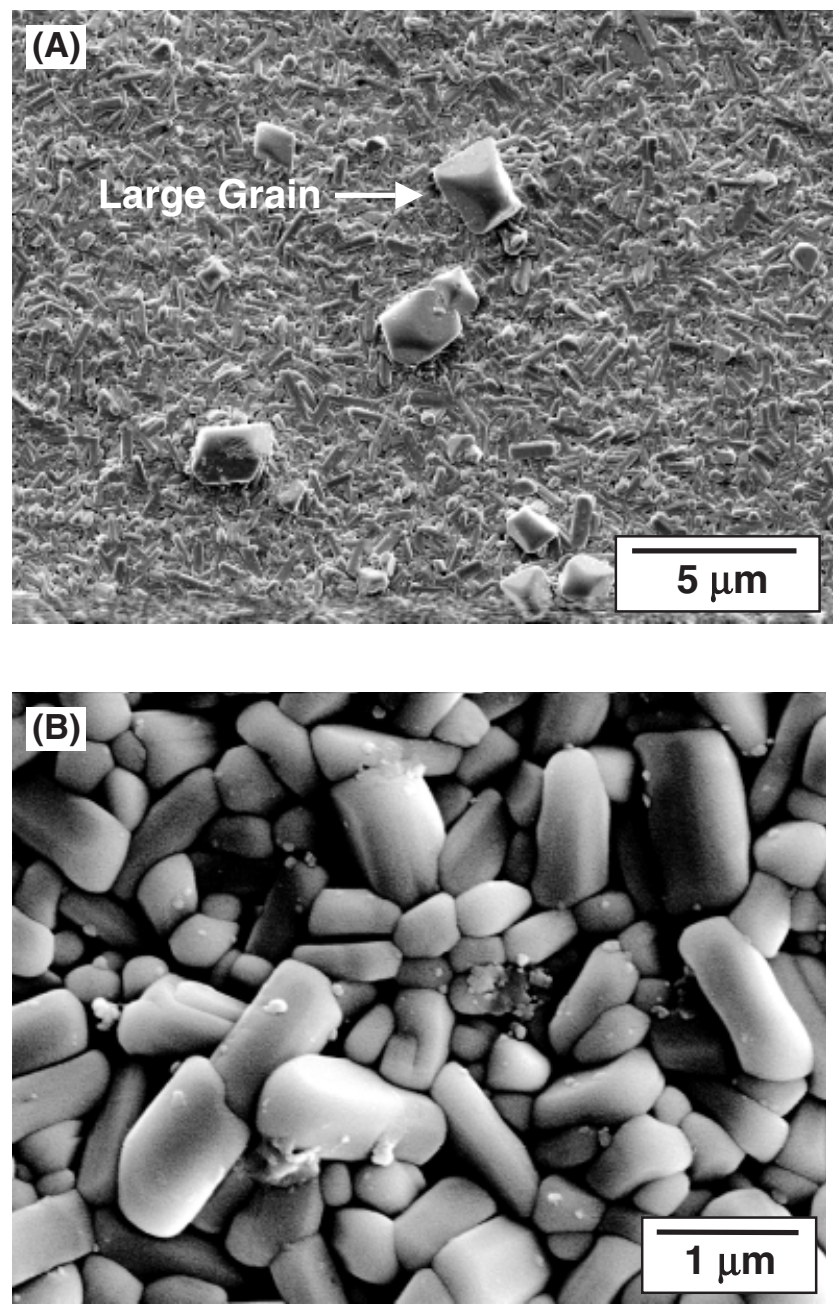

Fig. 6. Scanning electron micrographs of $\mathrm{Bi}-\mathrm{Ba}-\mathrm{Nd}-\mathrm{Titania}$ material sintered at $980^{\circ} \mathrm{C}$ in air for $10 \mathrm{~h}$ illustrating (A) large grains at low magnification and (B) fine matrix grains at high magnification.

that when Bi-containing oxides are added into $\mathrm{BaO}-\mathrm{Nd}_{2} \mathrm{O}_{3}-$ $\mathrm{TiO}_{2}$ ternary system, amounts of $\mathrm{Bi}^{3+}$ ion tend to substitute into $\mathrm{Nd}^{3+}$ sites. ${ }^{21-23}$

On the contrary, the peak of Bi element in the large grain became much stronger, as shown in Fig. 7(B). Although all the $\mathrm{Ba}$ peaks overlapped with the peaks of $\mathrm{Ti}$ or $\mathrm{Nd}$, it was believed

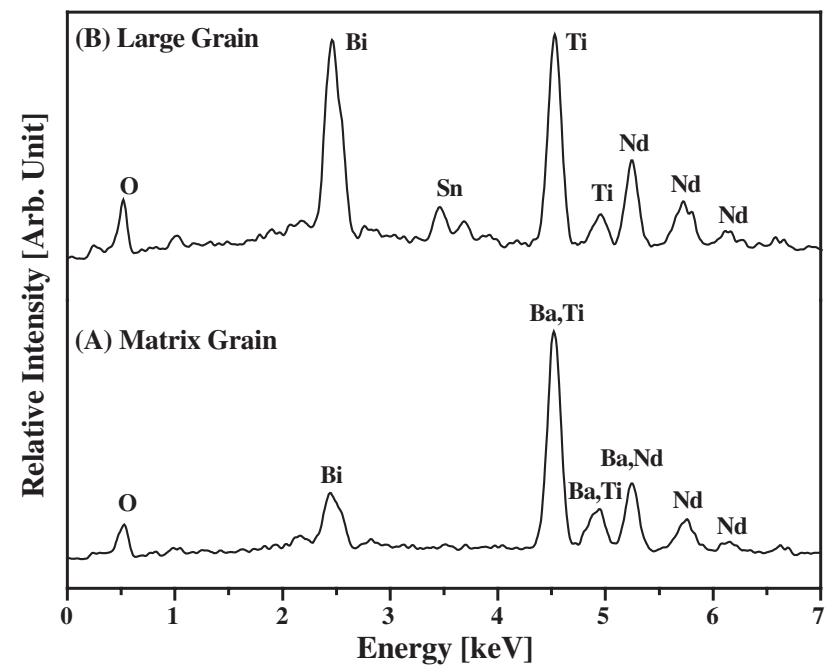

Fig. 7. Energy-dispersive spectrum analyses of (A) matrix grain and (B) large grain in $\mathrm{Bi}-\mathrm{Ba}-\mathrm{Nd}-$ Titania material sintered at $980^{\circ} \mathrm{C}$ for $10 \mathrm{~h}$ in air

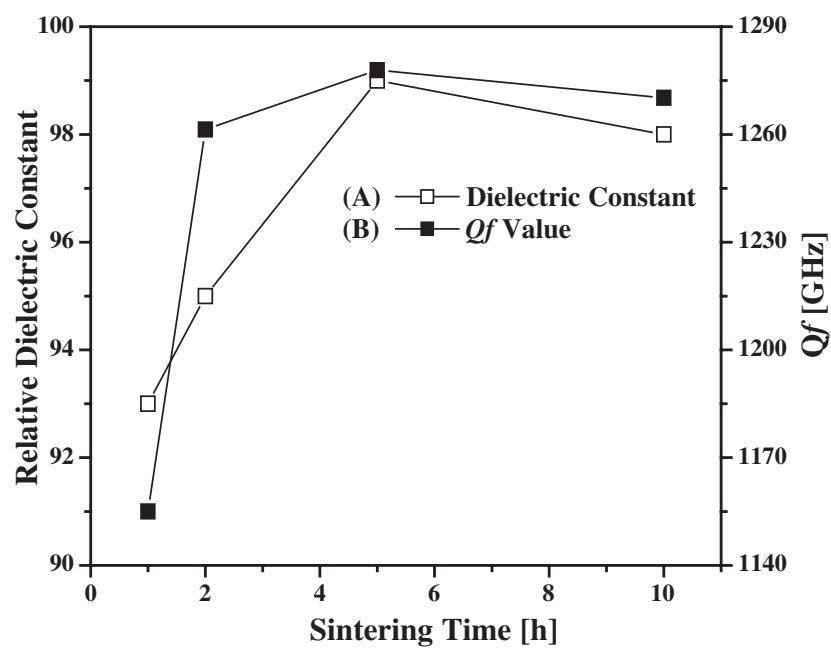

Fig. 8. (A) Dielectric constant and (B) $Q_{\mathrm{f}}$ value of $\mathrm{Bi}-\mathrm{Ba}-\mathrm{Nd}-\mathrm{Titania}$ material sintered at $980^{\circ} \mathrm{C}$ as a function of sintering time.

that this grain comprised of $\mathrm{Sn}$-substituted $\mathrm{Bi}-\mathrm{Nd}$-titanate that was correspondent to $\mathrm{Bi}_{3.6} \mathrm{Nd}_{0.4} \mathrm{Ti}_{3} \mathrm{O}_{12}$ crystalline structure, detected by XRD analysis. Such chemical compositions were also confirmed by EPMA.

Dielectric constant and $Q_{\mathrm{f}}$ value of the BBNT sample sintered at $980^{\circ} \mathrm{C}$ as a function of the dwelling time were measured, as shown in Figs. 8(A) and (B). As the dwelling time was increased up to $5 \mathrm{~h}$, the dielectric constant increased from 93 to 99 and the
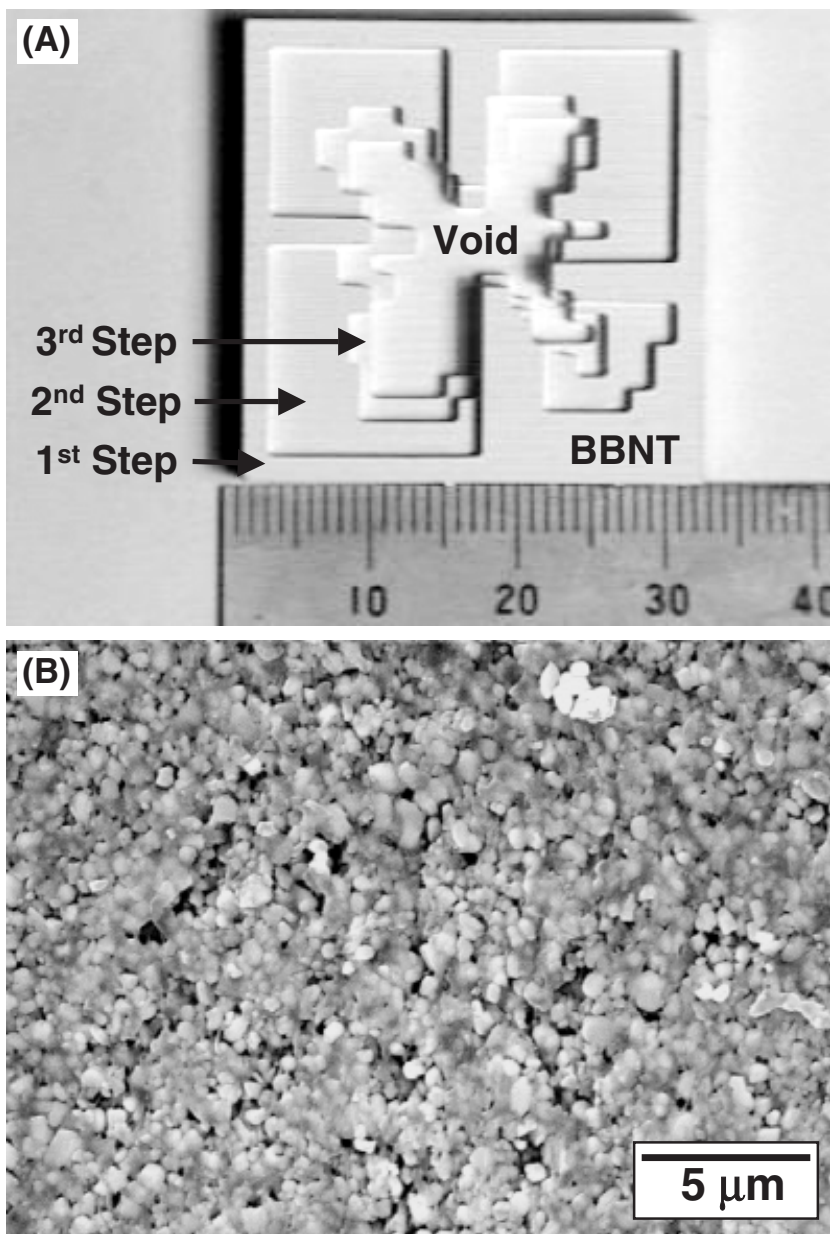

Fig. 9. (A) Optical micrograph of the machined $\mathrm{Bi}-\mathrm{Ba}-\mathrm{Nd}-\mathrm{Titania}$ (BBNT) block illustrating the three-dimensional void in three steps and (B) scanning electron micrograph of the as-machined surface illustrating good surface finish at scale of grain. 
$Q_{\mathrm{f}}$ value increased from 1155 to $1280 \mathrm{GHz}$. However, dielectric properties were slightly decreased after the longer dwelling of $10 \mathrm{~h}$, presumably due to the enhanced volatilization of $\mathrm{Bi}$ and $\mathrm{Sn}$. Similar results were observed for Bi-substituted $\mathrm{Ba}-\mathrm{Nd}-$ titanates. $^{23}$

\section{(3) Characterization of Textured Dielectric Substrate}

We chose a thermoplastic green machining to make a textured dielectric substrate. To utilize this process, the larger void should be placed over the smaller one because this process is based on a material removal by milling. Therefore, the material removal should be conducted in the sequence of third, second, and first because of their void geometries. For this sequence, the mirror image of the original design was prepared and modified further to eliminate the blind hole.

A thermoplastic BBNT block was precisely machined using a mini-CNC machine with a carbide-endmill. The predetermined amount of the material was removed in the specific position, consequently leaving a three-dimensional void in the green BBNT block, as shown in Fig. 9(A). After machining, good surface finish and edge retention without chipping in each step were observed. The surface damage of the machined sample at scale of grain is shown in Fig. 9(B). No defects, such as tearing or pull-outs of ceramic particles, were observed due to the good machinability of thermoplastic compound, as previously reported.

After sintering at $980^{\circ} \mathrm{C}$ for $5 \mathrm{~h}$ in air, the sample exhibited good shape tolerance without generating any defects, such as cracking and distortion, as shown in Fig. 10(A). A complicated
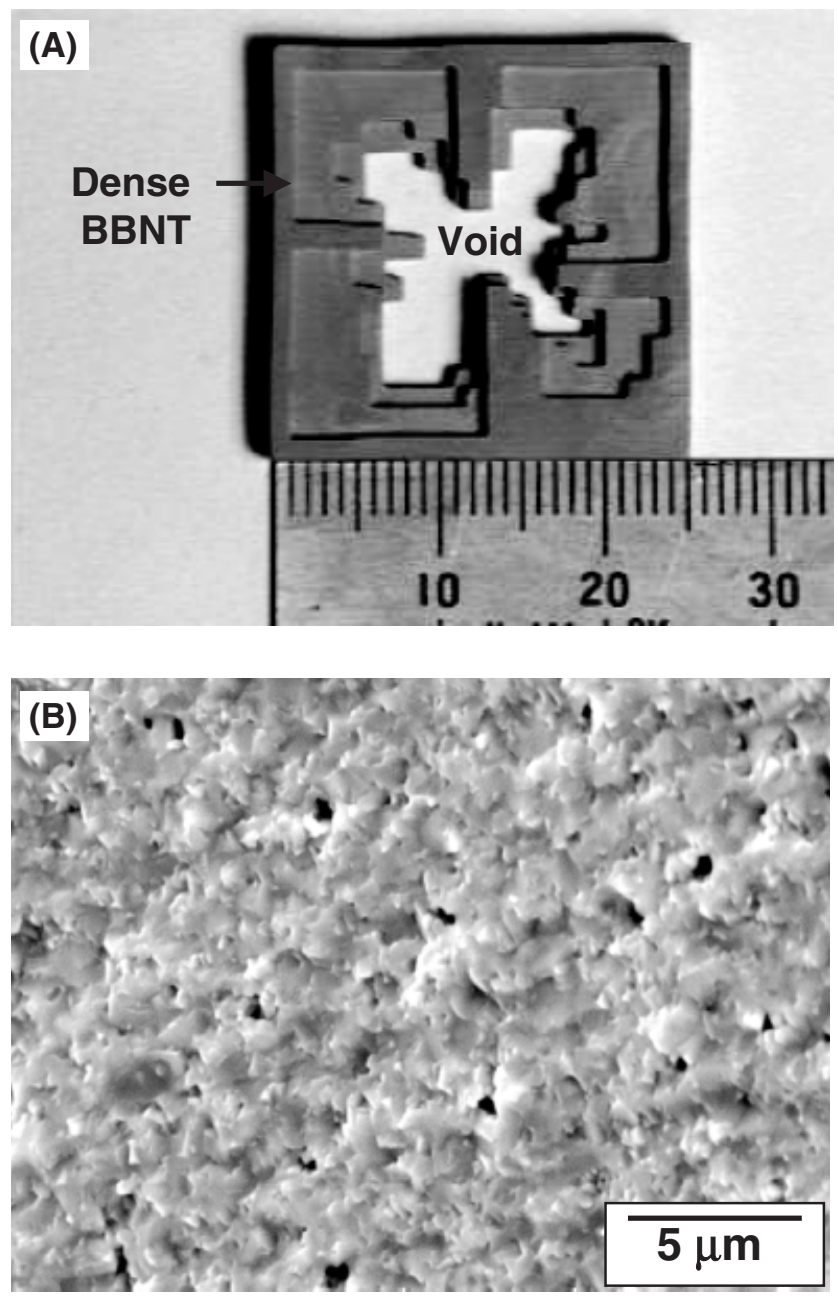

Fig. 10. Scanning electron micrographs of (A) as-fired sample and (B) fracture surface of $\mathrm{Bi}-\mathrm{Ba}-\mathrm{Nd}-$ Titania material after sintering at $980^{\circ} \mathrm{C}$ for $5 \mathrm{~h}$.

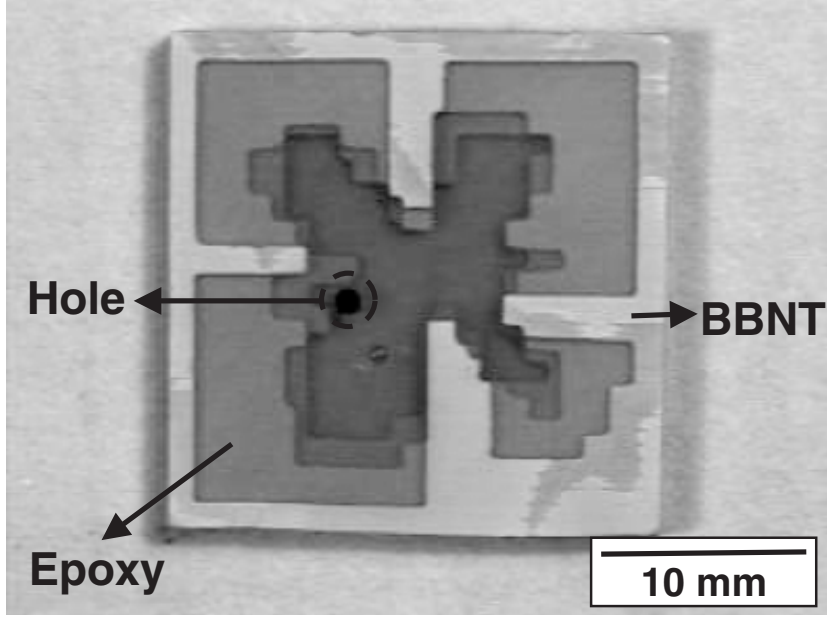

Fig. 11. Optical micrograph illustrating the textured dielectric substrate, consisting of dense $\mathrm{Bi}-\mathrm{Ba}-\mathrm{Nd}-\mathrm{Titania}(\mathrm{BBNT})$ and epoxy, and the hole in epoxy region for probe feed.

three-dimensional void in the dense BBNT sample was distorted negligibly. At high magnification, the fracture surface revealed the negligible pores and defects (Fig. 10(B)), implying almost full densification. As expected, the sample showed predetermined dimensions of $25 \mathrm{~mm} \times 25 \mathrm{~mm} \times 3.175 \mathrm{~mm}$ after $19 \%$ linear shrinkage.

The void in the dense BBNT block was filled by a commercial dielectric epoxy to fabricate a textured dielectric substrate, as shown in Fig. 11. Care was taken to avoid defects associated with curing shrinkage of epoxy. An adhesion between BBNT and epoxy was observed without generating interfacial delamination and cracking of BBNT or the epoxy region. Furthermore, a hole was prepared in the epoxy region for a probe feed.

\section{(4) Measurement of Antenna Performance}

The return loss of the patch antenna using this textured dielectric substrate was measured and compared with the simulated result, as shown in Figs. 12(A) and (B). The measured return loss pattern was slightly shifted to the higher operating frequency. A $5 \mathrm{~dB}$ return loss bandwidth of $11.3 \%$ and $10 \mathrm{~dB}$ return loss bandwidth of $7.8 \%$ were obtained. Compared with the homogenous dielectric substrate (see Fig. 3(A)), 168\% bandwidth improvement was achieved, while maintaining the same physical size. The measured gain was $2 \mathrm{~dB}$. Antenna quality factor

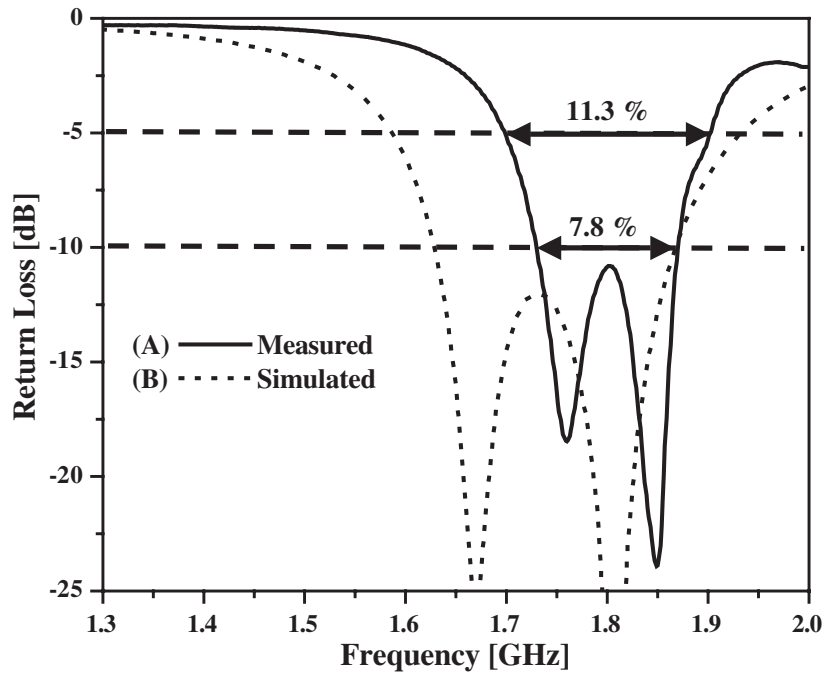

Fig. 12. (A) Measured and (B) simulated return loss of the patch antenna using the textured dielectric substrate. 


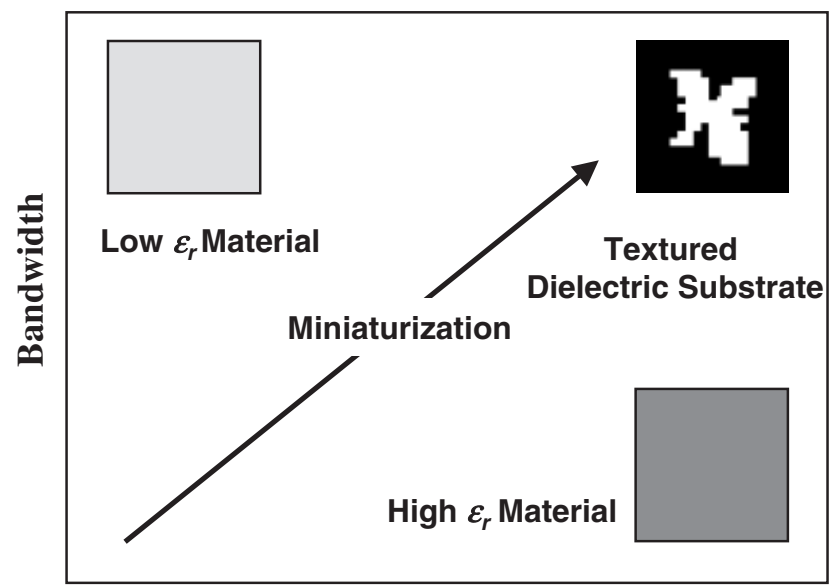

Size Reduction

Fig. 13. A schematic illustrating antenna performance using homogenous dielectric constant $\left(\varepsilon_{\mathrm{r}}\right)$ materials and a textured dielectric substrate.

(AQF) was calculated by taking account of BW, gain, and antenna size. The AQF value of the textured dielectric substrate increased significantly by a factor of 4.5 compared with that of the homogenous dielectric substrate.

To overcome the trade-off relationship between physical size and bandwidth of a patch antenna, we proposed a textured dielectric substrate instead of a homogenous dielectric substrate. Figure 13 illustrates the relationship between the size and bandwidth of patch antenna using a homogenous and a textured dielectric substrate. A higher dielectric constant substrate can offer a smaller patch antenna but narrow bandwidth, while a lower dielectric constant substrate offers a broader bandwidth but larger size. On the contrary, a broad bandwidth with a smaller size (i.e., miniaturization) could be achieved using a textured dielectric substrate.

\section{Summary and Conclusions}

A textured dielectric substrate was fabricated using a thermoplastic green machining for a broadband miniature antenna. This textured dielectric substrate comprised of three steps, in which each layer possessed the optimized distribution of BBNT and epoxy. A thermoplastic BBNT block was precisely machined using a mini-CNC machine according to the pre-determined design and sintered at $980^{\circ} \mathrm{C}$ for various dwelling times. The BBNT sample was mainly composed of Bi-substituted Ba$\mathrm{Nd}$-titanate grains along with $\mathrm{Sn}$-substituted $\mathrm{Sn}-\mathrm{Nd}$-titanate and $\mathrm{BaTi}_{4} \mathrm{O}_{9}$ as secondary phases. The good microwave dielectric properties with dielectric constant of 99 and $Q_{\mathrm{f}}$ value of 1280 $\mathrm{GHz}$ were obtained after sintering at $980^{\circ} \mathrm{C}$ for $5 \mathrm{~h}$. The three- dimensional void in the dense BBNT block was filled with an epoxy to prepare a textured dielectric substrate. This new substrate with texture exhibited remarkably improved bandwidth $(168 \%)$ compared with a homogenous dielectric substrate, while maintaining the same physical size.

\section{References}

${ }^{1}$ H. F. Lee and W. Chen, Advances in Microstrip and Printed Antennas. Wiley, New York, 1997.

${ }^{2}$ D. M. Pozar, "Microstrip Antennas,” Proc. IEEE, 80 [1] 79-91 (1992).

${ }^{3}$ G. P. Gauthier, A. Courtay, and G. M. Rebeiz, "Microstrip Antennas on Synthesized Low Dielectric-Constant Substrates," IEEE Trans. Antennas Propag. 45 [8] 1310-4 (1997).

${ }^{4}$ I. S. Ghosh, A. Hilgers, T. Schlenker, and R. Porath, "Ceramic Microwave Antennas for Mobile Applications," J. Eur. Ceram. Soc., 21 [15] 2621-8 (2001).

${ }^{5}$ G. Kiziltas, C. Yilmaz, J. L. Volakis, N. Kikuchi, and J. W. Halloran, "Design of Metamaterial Textures for Microwave Applications;" pp. 388-91, IEEE Symposium on Antennas and Propagation, II, 2002.

${ }^{6}$ G. Kiziltas, J. L. Volakis, and N. Kikuchi, "Metamaterial Design via the Density Method;" pp. 748-51, IEEE Symposium on Antennas and Propagation, I, 2002.

${ }^{7}$ G. Kiziltas, D. Psychoudakis, J. L. Volakis, and N. Kikuchi, "Topology Optimization of Dielectric Substrates for Bandwidth Improvements of Patch Antennas," IEEE Trans. Antennas Propag. 51 [10] 2732-43 (2003).

${ }^{8}$ Y. H. Koh, A. Knapp, J. W. Halloran, H. W. Kim, and H. E. Kim, "Microstructural Evolution and Its Effect on Dielectric Properties of Ca-Mg-Silicate Glass Ceramics," J. Mater. Res. (in review).

${ }^{9}$ M. L. Griffith and J. W. Halloran, "Freeform Fabrication of Ceramics Via Stereolithography," J. Am. Ceram. Soc., 79 [10] 2601-8 (1996).

${ }^{10} \mathrm{~J}$. R. Christopher "Novel Electroactive Ceramic Architectures by Indirect Solid Freeform Fabrication;" PhD thesis. University of Michigan, Ann Arbor, MI, 2001.

${ }^{11}$ Y. H. Koh and J. W. Halloran, "Green Machining of Thermoplastic CeramicEthylene Ethyl Acrylate/Isobutyl Methacrylate Compound," J. Am. Ceram. Soc., 87 [8] 1575-7 (2004).

${ }^{12}$ J. H. Song and J. R. G. Evans, "On the Machinability of Ceramic Compacts," J. Eur. Ceram. Soc., 17 [14] 1665-73 (1997).

${ }^{13}$ T. Besshi, T. T. Sato, and I. Tsutsui, "Machining of Alumina Green Bodies and Their Dewaxing," J. Mater. Process. Tech., 95 [1-3] 133-8 (1999).

${ }^{14}$ S. D. Nunn and G. H. Kirby, "Green Machining of Gelcast Ceramic Materials," Ceram. Eng. Sci. Proc., 17 [3] 209-13 (1996).

${ }^{15}$ Technical publication of FERRO TAPE-A6, Ferro Corp., Santa Barbara, CA, 1996.

${ }^{16}$ S. H. Knickerbocker, A. H. Kumar, and L. W. Herron, "Cordierite GlassCeramics for Ceramic Packaging," Am. Ceram. Soc. Bull., 72 [1] 90-5 (1993).

${ }^{17}$ S. X. Dai, R. F. Huang, and D. L. Wilcox, "Use of Titanates to Achieve a Temperature-Stable Low-Temperature Cofired Ceramic Dielectric for Wireless Applications," J. Am. Ceram. Soc., 85 [4] 828-32 (2002).

${ }^{18}$ O. Dernovsek, A. Naeini, G. Preu, W. Wersing, M. Eberstein, and W. A. Schiller, "LTCC Glass-Ceramic Composites for Microwave Applications," J. Eur. Ceram. Soc., 21 [10-11] 1693-7 (2001).

${ }^{19}$ B. W. Hakki and P. D. Coleman, "A Dielectric Resonator Method of Measuring Inductive Capacities in the Millimeter Range," IRE Trans. Microwave Theory Tech., 8, 402-10 (1960).

${ }^{20}$ D. Kaifez and P. Guillion, Dielectric Resonators, pp. 327-76. Artech House, Norwood, MA, 1986.

${ }^{21}$ M. Valant, D. Suvorov, and D. Kolar, "Role of $\mathrm{Bi}_{2} \mathrm{O}_{3}$ in Optimizing the Dielectric Properties of $\mathrm{Ba}_{4}{ }_{5} \mathrm{Nd}_{9} \mathrm{Ti}_{18} \mathrm{O}_{54}$ Based Microwave Ceramics," J. Mater. Res., 11 [4] 928-31 (1996).

${ }^{22}$ Y. J. Wu and X. M. Chen, "Bismuth/Samarium Cosubstituted $\mathrm{Ba}_{6-3 x} \mathrm{Nd}_{8+2 x-}$ $\mathrm{Ti}_{18} \mathrm{O}_{54}$ Microwave Dielectric Ceramics," J. Am. Ceram. Soc., 83 [7] 1837-9 (2000).

${ }^{23}$ Y. J. Wu and X. M. Chen, "Modified $\mathrm{Ba}_{6-3 \mathrm{x}} \mathrm{Nd}_{8+2 \mathrm{x}} \mathrm{Ti}_{18} \mathrm{O}_{54}$ Microwave Dielectric Ceramics," J. Eur. Ceram. Soc., 19 [6-7] 1123-6 (1999). 